\title{
Associations between home and school neighbourhood food environments and adolescents' fast-food and sugar-sweetened beverage intakes: findings from the Olympic Regeneration in East London (ORiEL) Study
}

\author{
Martine Shareck ${ }^{1, *}, \dagger$, Daniel Lewis ${ }^{1}$, Neil R Smith ${ }^{2}$, Christelle Clary $^{1}$ and Steven Cummins ${ }^{1}$ \\ ${ }^{1}$ Department of Social and Environmental Health Research, Public Health Policy, London School of Hygiene and \\ Tropical Medicine, London, UK: ${ }^{2}$ National Centre for Social Research, London, UK
}

Submitted 8 November 2017: Final revision received 29 March 2018: Accepted 8 May 2018: First published online 2 July 2018

\begin{abstract}
Objective: To examine associations between availability of fast-food restaurants and convenience stores in the home and school neighbourhoods, considered separately and together, and adolescents' fast-food and sugar-sweetened beverage (SSB) intakes. Design: Cross-sectional observational study.

Setting: East London, UK.

Subjects: Adolescents ( $n$ 3089; aged $13-15$ years) from the Olympic Regeneration in East London (ORiEL) Study self-reported their weekly frequency of fast-food and SSB consumption. We used food business addresses collected from local authority registers to derive absolute (counts) and relative (proportions) exposure measures to fast-food restaurants and convenience stores within $800 \mathrm{~m}$ from home, school, and home and school combined. Associations between absolute and relative measures of the food environment and fast-food and SSB intakes were assessed using Poisson regression models with robust standard errors.

Results: Absolute exposure to fast-food restaurants or convenience stores in the home, school, or combined home and school neighbourhoods was not associated with any of the outcomes. High SSB intake was associated with relative exposure to convenience stores in the residential neighbourhood (risk ratio $=1.45 ; 95 \% \mathrm{CI}$ $1.08,1.96)$ and in the home and school neighbourhoods combined (risk ratio $=1 \cdot 69 ; 95 \%$ CI $1 \cdot 11,2 \cdot 57)$.

Conclusions: We found no evidence of an association between absolute exposure to fast-food restaurants and convenience stores around home and school and adolescents' fast-food and SSB intakes. Relative exposure, which measures the local diversity of the neighbourhood food environment, was positively associated with SSB intake. Relative measures of the food environment may better capture the environmental risks for poor diet than absolute measures.
\end{abstract}

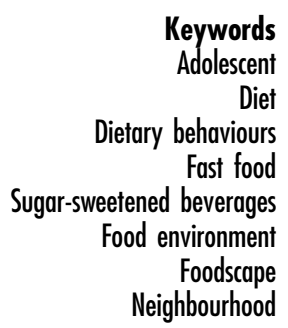

Poor diet is a key risk factor for a range of health problems including excess weight and related disorders such as type 2 diabetes and $\mathrm{CVD}^{(1)}$. High intakes of fast food and sugarsweetened beverages (SSB) are major contributors to poor dietary quality among young people $\mathrm{e}^{(2,3)}$, with a recent study using data from thirty-six countries reporting that $51.3 \%$ of adolescents consume fast food at least once per week $^{(4)}$. Fast food is characterized by large portion sizes and high energy, salt, sugar and saturated fat contents, and

$\dagger$ Current address: Division of Social and Behavioural Health Sciences, Dalla Lana School of Public Health, University of Toronto, 155 College Street, Toronto M5T 3M7, Canada. is often consumed with $\mathrm{SSB}^{(5)}$. SSB are responsible for the largest proportion of refined sugar intake in 11-18-yearolds $^{(6)}$ and, similar to fast food, contribute to weight gain $^{(7)}$. As a critical transition period during which unhealthy diets may become established and track into adulthood $^{(8,9)}$, adolescence provides a window of opportunity for intervention.

In addition to personal and social characteristics ${ }^{(10)}$, the food environment, which is commonly characterized as the 'number, type, location, and accessibility of food outlets such as grocery stores, convenience stores, fast food restaurants, and full-service restaurants, ${ }^{(11)}$, has emerged as a key contributor to dietary behaviour ${ }^{(12-14)}$ and excess 
weight ${ }^{(15,16)}$. The food environment may influence dietary behaviours through structural differences in availability and access to components of healthy and less healthy diets. In one study, adolescents were more likely to selfpurchase from fast-food restaurants or convenience stores when they lived or attended school in neighbourhoods characterized by a high density of such stores ${ }^{(17)}$. Food retailers may also provide visual and olfactory cues provoking the desire to purchase and eat certain foods ${ }^{(18-21)}$, a mechanism which may be even stronger when energydense foods are promoted since young people tend to have a general preference for such foods ${ }^{(22)}$. A high concentration of similar food retailers may also be indicative of a more price-competitive market, thereby decreasing the cost of certain foods compared with others. This may be important for adolescents, who tend to be pricesensitive given their restricted financial means and who are less likely than adults to weigh the nutritional implications of their poor dietary choices against price considerations $^{(23)}$. The dominant category of food establishments in a given environment may also reflect local market demand for particular food types and relate to the normalization of certain dietary behaviours ${ }^{(24)}$.

In the light of these hypothesized mechanisms, policy makers see the potential in intervening in the food environment to improve diet and reduce obesity ${ }^{(25)}$. This is despite equivocal evidence for an association between the food environment and young people's dietary behaviours $^{(12,13)}$. While some studies have found that the density of fast-food restaurants or convenience stores around the home was positively associated with young people's purchase $^{(17)}$ and intake of fast food ${ }^{(26-28)}$ or SSB $^{(29-31)}$, others have not $^{(17,18,32)}$. In one study that investigated proximity rather than density, Skidmore et al. found that living further away from a fast-food restaurant or convenience store was associated with less frequent consumption of sugary drinks ${ }^{(33)}$. Studies of fast-food retailer availability in the school neighbourhood have tended to report null associations with fast-food ${ }^{(26,32,34,35)}$ and SSB intake $(30,32,36,37)$, although school density and proximity to fast-food restaurants have been found to positively relate to fast-food intake and SSB consumption ${ }^{(31,38)}$.

Previous research on adolescents has focused primarily on the effect of the food environment in the home neighbourhood and to a lesser extent the school neighbourhood $^{(12)}$. Young people spend most of their time either at home or in school, making these two settings central to their daily lives and activity spaces. Despite this, studies have rarely quantified the effect of exposure to both settings considered together ${ }^{(26,32,36,39)}$, hampering exploration of the cumulative impact of multiple environmental exposures occurring across the day that may affect diet. A second limitation is an almost exclusive focus on environmental exposures based upon the presence of specific types of food retailers in a given area (i.e. absolute availability) and less consideration of measures of relative availability, where exposure is defined as the number of specific types of food retailers expressed as a proportion of all food establishments in an area or as the ratio of healthy to unhealthy food outlets ${ }^{(12,16)}$. Unlike absolute measures, relative measures characterize an individual's simultaneous exposure to a wide array of food retailers from which to purchase food ${ }^{(24)}$. Relative measures thus account for the co-location of healthy and unhealthy food outlets, providing an indication of local food retail diversity, and have been found to predict dietary behaviours more consistently in adults ${ }^{(40-42)}$.

In the present paper we explore the associations between the home and school neighbourhood food environments, considered separately and together, and high consumption of fast food and SSB using both absolute and relative exposure measures. We hypothesized that: (i) a high availability of fast-food restaurants and convenience stores in the home and school neighbourhoods considered separately would be associated with a higher consumption of fast food and SSB; (ii) the availability of fast-food restaurants and convenience stores in the home and school neighbourhoods considered together would be more strongly associated with fast food and SSB consumption than availability in each setting taken separately; and (iii) associations with relative measures would be stronger than with absolute measures.

\section{Methods}

\section{Data collection}

Data came from wave 3 ( $n$ 3089) of the Olympic Regeneration in East London (ORiEL) Study, a prospective cohort study of adolescents and their parents which evaluated the health impacts of urban regeneration following the London 2012 Olympic Games ${ }^{(43)}$. Adolescent participants were recruited from twenty-five randomly selected secondary schools in four boroughs of East London, UK: Tower Hamlets, Hackney, Barking and Dagenham, and Newham. Year 9 students (aged 13-15 years) completed a selfadministered paper-based questionnaire in class time under researcher supervision. Data collection ran from January to July 2014. Full details on study recruitment and data collection are described elsewhere ${ }^{(43)}$.

\section{Measures}

\section{Fast-food and sugar-sweetened beverage intakes}

Weekly frequency of fast-food intake was based on two questions adapted from earlier studies ${ }^{(26,44,45)}$ : (i) 'How often do you eat takeaways or fast food at home?' and (ii) 'How often do you eat takeaways or fast food away from home?'. Examples of typical sources of fast food were given (Pizza Hut, Burger King, Subway, McDonald's, Perfect Fried Chicken). These questions were found to have good internal reliability in a sample of young 
adults $^{(45)}$. Five response options were available: 'never or rarely', 'less than one day a week', ' 2 to 3 days a week', ' 4 to 6 days a week' and 'every day'. Responses to each question were dichotomized as fast food consumed $\geq 2-3 \mathrm{~d} /$ week and $<2-3 \mathrm{~d} /$ week $^{(21,38,45)}$. We also analysed fast-food intake regardless of where it was consumed by comparing participants who ate fast food $\geq 2-3 \mathrm{~d} /$ week at home or away with less frequent consumers. SSB intake was assessed with the question 'How often do you drink fizzy drinks?' with five possible responses: 'never', 'rarely', 'at least once a week', 'once a day' and 'more than once per day'. SSB intake was dichotomized as $\geq 1$ time/d and $<1$ time $/ \mathrm{d}^{(32)}$. Fast food and SSB outcomes were analysed separately.

\section{Availability of fast-food restaurants and convenience stores}

Data on food businesses (full name, address and category of food retailer) were extracted from local authority registers of the four study and adjacent boroughs for the same time period as the individual-level data were collected. In the UK, all food businesses are obliged by the Food Standards Agency to register with their local environmental health authority $28 \mathrm{~d}$ prior to opening and to inform the authority of any status changes or closures ${ }^{(46)}$. Food establishments were classified using the following fifteen mutually exclusive categories: chain supermarkets; independent supermarkets; discount retailers; ethnicspecific supermarkets; affiliated franchise stores (e.g. Spar, CostCutter); convenience stores Type A (mini-markets selling fresh fruits and vegetables); convenience stores Type B (newsagent, tobacconist or confectioner); meat and fish shops; fruit and vegetable shops; other specialist food stores; bakeries; full-service restaurants; chain fast-food restaurants, independent fast-food restaurants; and coffee shops and sandwich bars. Food retailers that were not assigned a retailer type in the register were incorporated in the existing classification using store name and visual appearance in Google Street View. Fast-food restaurants encompassed independent or multi-premises restaurant businesses offering foods and drinks in a selfservice manner to eat in, or by collection or delivery to take away; while convenience stores were defined as small stores selling a limited range of foods. In a validation study, food services data which included fast-food restaurants showed high positive predictive value ( $\mathrm{PPV}=0.96 ; 95 \% \mathrm{CI}$ 0.94, 0.98) when compared with contemporary street photography from Google and Bing search engines (D Lewis and S Cummins, unpublished results).

Residential, school and food business addresses were geocoded using a Python script which matched reported addresses with authoritative address location data provided by the Ordnance Survey Address Layer 2 database $^{(47)}$. Home and school locations were used as anchors to create $800 \mathrm{~m}$ pedestrian road network buffers. A distance of $800 \mathrm{~m}$ corresponds approximately to a $10 \mathrm{~min}$ walk and has previously been used to study environmental correlates of young people's dietary behaviours $^{(26,30)}$. For each buffer, we computed the number of (i) chain and independent fast-food restaurants, (ii) convenience stores (both types as described above) and (iii) all fifteen types of food establishments combined. For the combined buffer, the numbers for the home and school buffers were summed but avoided double counting within any spatial overlap. Using these metrics, absolute availability measures were computed as the number of (i) fast-food restaurants or (ii) convenience stores in each buffer. Relative availability measures were defined as the proportion of all food establishments that were fast-food restaurants (i/iii) or convenience stores (ii/iii) ${ }^{(42,48)}$. Availability measures were treated as continuous variables to allow comparison with other studies ${ }^{(49)}$.

\section{Covariates}

Individual-level covariates considered for inclusion in the models were based on previously published work in the field and included age (continuous), sex (male/female), ethnicity (White UK/Black/South Asian/Other) and having free school meals (yes/no). Residential neighbourhood disadvantage was considered a potential confounder and operationalized as the 2015 relative income deprivation index categorized into quintiles based on the London distribution for the lower super output area in which the home address was located. Residential neighbourhood disadvantage was not found to be associated with exposures and outcomes in bivariate analyses, so was excluded from subsequent analyses.

\section{Analyses}

Out of 3089 participants, between 17.5 and $18.5 \%$ had missing data on one or more of the dietary outcomes, $14.0 \%$ did not have residential exposure measures, $2.3 \%$ were missing free school meals information and $0.9 \%$ had missing data for ethnicity. Missingness patterns were assessed and missing data were imputed under a 'missing at random' assumption using the multivariate imputation using chained equations method ${ }^{(50)}$. The imputation model included all variables from the final models along with the auxiliary variables BMI $Z$-score (continuous) and time lived in the neighbourhood (more $v$. less than 1 year). A burn-in period of twenty iterations was specified and a total of thirty imputed data sets were produced after 600 iterations. Diagnostic checks were performed by comparing the distributions of observed and imputed values and examining trace plots for chain convergence ${ }^{(51)}$.

We used generalized linear models with Poisson distribution and log link function to perform the regression of fast-food intake $v$. fast-food restaurant availability measures, and of SSB intake $v$. convenience store availability measures. Poisson regression with robust standard errors was preferred over logistic regression since it provides 
unbiased estimates of the adjusted relative risk when outcomes are highly prevalent $(>10 \%)^{(52)}$. Individual-level models were fitted since school-level clustering was found to be minimal (intraclass coefficients ranging from 0.01 to 0.05). Crude and adjusted relative risks (RR) and 95\% confidence intervals were estimated comparing high with low consumers of fast food or SSB. Analyses were performed using the statistical software package Stata version 15 (2017) on the complete imputed data set (without deleting imputed outcomes) as recommended when estimating relative risks ${ }^{(53)}$.

\section{Results}

Table 1 provides means and $95 \%$ CI for participants' individual-level characteristics based on the imputed data sets. Girls comprised $43.3 \%$ of the imputed samples, which were $16.8 \%$ White UK, $22.9 \%$ South Asian and $22.3 \%$ Black. A third (33.3\%) of participants received free school meals. About a quarter of the sample consumed fast food $\geq 2-3 \mathrm{~d} /$ week at home $(27.3 \%)$ or away $(25.7 \%)$, while $36.7 \%$ frequently consumed fast food at and/or away from home. Nearly half (47.0\%) of participants reported drinking SSB $\geq 1$ time/d (Table 1 ).

Food environment characteristics for the imputed data sets are presented in Table 2. There were on average 11.5, 10.0 and 19.6 fast-food restaurants in home, school and combined neighbourhoods, respectively. Expressed as a proportion, fast-food restaurants represented between 21 and $25 \%$ of all food establishments. There were on average 11.1, 11.6 and 20.6 convenience stores in participants' home, school and combined neighbourhoods, which accounted for 28 to $31 \%$ of all food establishments in these settings (Table 2).

Results from regression models for the association between the absolute availability of fast-food restaurants and convenience stores in the home, school, and combined home and school neighbourhoods and fast-food or SSB intake are presented in Table 3. For all outcomes, estimates from both unadjusted and fully adjusted models controlling for age, sex, ethnicity and free school meals approximated the null value.

Table 4 shows results for the association between relative measures of the food environment in each setting and high intake of fast food or SSB. Associations between exposure to fast-food restaurants in the home and combined home and school neighbourhoods and high fastfood intake were in the expected, positive direction, but none of the fully adjusted models reached statistical significance. The proportion of fast-food restaurants around school was inversely associated with fast-food intake, albeit non-significantly so. An increased proportion of convenience stores in all three settings was associated with higher SSB intake, with results reaching statistical significance for the home neighbourhood ( $R R=1.45 ; 95 \%$ CI 1.08, 1.96) and the combined home and school neighbourhoods ( $\mathrm{RR}=1 \cdot 69 ; 95 \% \mathrm{CI} 1 \cdot 11,2 \cdot 57)$.

\section{Sensitivity analyses}

We ran several sensitivity analyses to test model robustness. Results of analyses of food environment measures computed for buffers of 400 and $600 \mathrm{~m}$ did not differ qualitatively from those presented here, save for the relative availability of convenience stores around home which was not significantly associated with SSB intake, while the school neighbourhood availability was $(\mathrm{RR}=1 \cdot 30 ; 95 \% \mathrm{CI}$ $1.13,1.50$ and $\mathrm{RR}=1.36 ; 95 \% \mathrm{CI} 1.13,1.64$ for the 400 and $600 \mathrm{~m}$ buffer, respectively). In analysing the unhealthiest definitions of dietary behaviours (i.e. eating fast food $\geq 4$ times/week and drinking SSB $>1$ time/d), we found results to be robust across model specifications for absolute availability measures and both outcomes, and for relative

Table 1 Individual-level characteristics for 3089 adolescents aged 13-15 years from the Olympic Regeneration in East London (ORiEL) Study, January-July $2014^{*}$

\begin{tabular}{|c|c|c|c|}
\hline Individual-level characteristic & Mean & $95 \% \mathrm{Cl}$ & $\%$ missing \\
\hline Mean age (years) & $14 \cdot 1$ & $14 \cdot 1,14 \cdot 1$ & 0.0 \\
\hline Female (\%) & $43 \cdot 3$ & $41 \cdot 6,45 \cdot 1$ & 0.0 \\
\hline Ethnicity (\%) & & & 0.9 \\
\hline White UK & $16 \cdot 8$ & $15 \cdot 5,18 \cdot 2$ & \\
\hline South Asian & $22 \cdot 9$ & $21 \cdot 4,24 \cdot 4$ & \\
\hline Black & $22 \cdot 3$ & $21 \cdot 2,24 \cdot 2$ & \\
\hline Other & $37 \cdot 6$ & $35 \cdot 9,39 \cdot 3$ & \\
\hline Have free school meals (\%) & 33.3 & $31 \cdot 6,34.9$ & $2 \cdot 3$ \\
\hline \multicolumn{4}{|l|}{ Fast-food intake (\%) } \\
\hline$\geq 2-3 \mathrm{~d} /$ week at home & $27 \cdot 3$ & $25 \cdot 5,29 \cdot 1$ & $17 \cdot 5$ \\
\hline$\geq 2-3 \mathrm{~d} /$ week away from home & $25 \cdot 7$ & $24 \cdot 0,27 \cdot 4$ & $18 \cdot 0$ \\
\hline$\geq 2-3 \mathrm{~d} /$ week at and/or away from home & $36 \cdot 7$ & $34.8,38 \cdot 6$ & $18 \cdot 5$ \\
\hline \multicolumn{4}{|l|}{ SSB intake† (\%) } \\
\hline$\geq 1$ time $/ \mathrm{d}$ & $47 \cdot 0$ & $45 \cdot 1,49 \cdot 0$ & 17.5 \\
\hline
\end{tabular}

SSB, sugar-sweetened beverage.

${ }^{*}$ Descriptive statistics are for the imputed data sets.

†SSB intake approximated with intake of fizzy drinks. 
Table 2 Food environment characteristics for 3089 adolescents aged 13-15 years from the Olympic Regeneration in East London (ORiEL) Study, January-July $2014^{*}$

\begin{tabular}{|c|c|c|c|}
\hline Food environment characteristic & Mean & $95 \% \mathrm{Cl}$ & $\%$ missing \\
\hline Availability of fast-food restaurants around home & & & $14 \cdot 0$ \\
\hline Absolute† & 11.5 & $11 \cdot 1,11 \cdot 8$ & \\
\hline Relativeł & 0.25 & $0.25,0.26$ & \\
\hline Availability of fast-food restaurants around school & & & 0.0 \\
\hline Absolute† & $10 \cdot 0$ & $9 \cdot 8,10 \cdot 2$ & \\
\hline Relative $\ddagger$ & 0.21 & $0.21,0.22$ & \\
\hline Availability of fast-food restaurants around home and school & & & $14 \cdot 0$ \\
\hline Absolute† & 19.6 & $19 \cdot 2,20 \cdot 0$ & \\
\hline Relative $\ddagger$ & 0.25 & $0.25,0.25$ & \\
\hline Availability of convenience stores around home & & & $14 \cdot 0$ \\
\hline Absolute† & 11.1 & $10 \cdot 8,11.4$ & \\
\hline Relative & 0.28 & $0.27,0.28$ & \\
\hline Availability of convenience stores around school & & & 0.0 \\
\hline Absolute† & 11.6 & $11.3,11.8$ & \\
\hline Relativeł & 0.31 & $0.30,0.32$ & \\
\hline Availability of convenience stores around home and school & & & $14 \cdot 0$ \\
\hline Absolute† & $20 \cdot 6$ & $20 \cdot 2,21 \cdot 0$ & \\
\hline Relativeł & 0.28 & $0.27,0.28$ & \\
\hline
\end{tabular}

*Descriptive statistics are for the imputed data sets.

†Absolute availability is the number of fast-food restaurants or convenience stores in a given buffer.

†Relative availability is the proportion of all food establishments that are fast-food restaurants or convenience stores in a given buffer.

exposure to fast-food restaurants and fast-food intake. Contrary to results for consuming SSB $\geq 1$ time/d (bottom row of Table 4), the relative availability of convenience stores was not associated with consuming SSB $>1$ time/d (data not shown). When assessing exposure to convenience stores in addition to fast-food restaurants, where young people may also consume SSB, we found similar results to those presented here, with $\mathrm{RR}=1.41(95 \% \mathrm{CI}$ $1.10,1.79)$ and $\mathrm{RR}=1.44$ (95\% CI 1.05, 1.99) for the home neighbourhood and the combined home and school neighbourhoods, respectively (data not shown).

\section{Discussion}

In the present study we assessed associations between the home and school neighbourhood food environments, separately and combined, and fast-food and SSB consumption in adolescents. Our study fills a gap in the literature on young people's dietary behaviours, especially as they relate to the cumulative exposure to fast-food restaurants and convenience stores in the home and school neighbourhoods combined ${ }^{(12)}$. It also provides evidence specific to a high-density urban context (London, UK) which is of importance since findings from different cities may not be directly comparable because of differences in urban density, form, planning and legislation ${ }^{(54)}$.

We found no evidence of an association between the absolute availability of fast-food restaurants or convenience stores and fast-food or SSB intake, findings which add to the weight of evidence suggesting no effect for the home ${ }^{(18,32,36)}$ and school ${ }^{(26,30,32,34-37)}$ neighbourhoods on these dietary outcomes. The null associations found for absolute availability measures in our sample could possibly be explained by the relatively low heterogeneity in the food environment exposures. Indeed, few participants had no fast-food restaurant or convenience store in any given setting (Appendix 2), hampering the differentiation of those not exposed at all to these types of food establishments from those with some exposure, which might have been informative.

Our study is one of a handful to have employed relative measures of exposure to assess food environment diversity in relation to young people's dietary behaviours ${ }^{(12)}$. Researchers have recommended the exploration of both absolute and relative availability measures, with the latter seemingly providing more consistent positive associations between the local food environment and $\operatorname{diet}^{(40-42)}$. One suggested argument in favour of relative rather than absolute availability measures is that they better reflect the overall environment within which food-related choices are made. As suggested by Clary et al., individuals consciously and unconsciously weigh the various options available to them (and that they are aware of) and as such final decisions are not based solely on the knowledge of one single category of food outlet being present, but rather also involve consideration of potential alternatives ${ }^{(24)}$. Exposure to a disproportionate share of stores selling certain types of food (recently coined 'food swamps') may relate to intake through mechanisms involving a cumulative increase in exposure to point-of-sale marketing and environmental cues stimulating the desire to consume the advertised foods ${ }^{(48)}$. A high relative availability of food stores may also be indicative of higher competition between establishments and thus more enticing promotions and lower prices, as well as social normalization of intake ${ }^{(24)}$. As expected, we found that the more saturated the home or the combined home and school neighbourhoods were with fast-food restaurants or convenience stores, the higher the risk of consuming fast food and SSB frequently, although results 


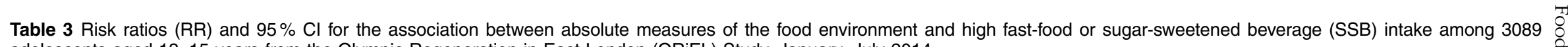
adolescents aged 13-15 years from the Olympic Regeneration in East London (ORiEL) Study, January-July 2014

\begin{tabular}{|c|c|c|c|c|c|c|c|c|c|c|c|c|}
\hline & \multicolumn{4}{|c|}{ Home } & \multicolumn{4}{|c|}{ School } & \multicolumn{4}{|c|}{ Home and school combined } \\
\hline & \multicolumn{2}{|c|}{ Unadjusted } & \multicolumn{2}{|c|}{ Adjusted* } & \multicolumn{2}{|c|}{ Unadjusted } & \multicolumn{2}{|c|}{ Adjusted $^{*}$} & \multicolumn{2}{|c|}{ Unadjusted } & \multicolumn{2}{|c|}{ Adjusted* } \\
\hline & $\mathrm{RR}$ & $95 \% \mathrm{Cl}$ & $\mathrm{RR}$ & $95 \% \mathrm{Cl}$ & RR & $95 \% \mathrm{Cl}$ & RR & $95 \% \mathrm{Cl}$ & $\mathrm{RR}$ & $95 \% \mathrm{Cl}$ & $\mathrm{RR}$ & $95 \% \mathrm{Cl}$ \\
\hline \multicolumn{13}{|l|}{ Exposure: number of fast-food restaurants } \\
\hline At home & 1.00 & $1.00,1.01$ & 1.00 & $1.00,1.01$ & 0.98 & $0.97,0.99$ & 0.98 & $0.97,0.99$ & 1.00 & $0.99,1.00$ & 1.00 & $0.99,1.00$ \\
\hline Away from home & 1.00 & $0.99,1.01$ & 1.00 & $0.99,1.01$ & 0.98 & $0.98,1.00$ & 0.99 & $0.98,1.00$ & 1.00 & $0.99,1.00$ & 1.00 & $0.99,1.00$ \\
\hline At home and/or away & 1.00 & $0.99,1.01$ & 1.00 & $0.99,1.00$ & 0.99 & $0.98,1.00$ & 0.99 & $0.98,1.00$ & 1.00 & $0.99,1.00$ & 1.00 & $0.99,1.00$ \\
\hline \multicolumn{13}{|l|}{ Exposure: number of convenience stores } \\
\hline Drinking SSB $\geq 1$ time/dł & 1.00 & $0.99,1.00$ & 1.00 & $0.99,1.00$ & 1.00 & $0.99,1.00$ & 1.00 & $0.99,1.00$ & 1.00 & $0.99,1.00$ & 1.00 & $0.99,1.00$ \\
\hline
\end{tabular}

TReference category is $<1$ time/d.

Table 4 Risk ratios (RR) and $95 \% \mathrm{Cl}$ for the association between relative measures of the food environment and high fast-food or sugar-sweetened beverage (SSB) intake among 3089 adolescents aged 13-15 years from the Olympic Regeneration in East London (ORiEL) Study, January-July 2014

\begin{tabular}{|c|c|c|c|c|c|c|c|c|c|c|c|c|}
\hline & \multicolumn{4}{|c|}{ Home } & \multicolumn{4}{|c|}{ School } & \multicolumn{4}{|c|}{ Home and school combined } \\
\hline & \multicolumn{2}{|c|}{ Unadjusted } & \multicolumn{2}{|c|}{ Adjusted ${ }^{*}$} & \multicolumn{2}{|c|}{ Unadjusted } & \multicolumn{2}{|c|}{ Adjusted $^{*}$} & \multicolumn{2}{|c|}{ Unadjusted } & \multicolumn{2}{|c|}{ Adjusted* } \\
\hline & RR & $95 \% \mathrm{Cl}$ & $\mathrm{RR}$ & $95 \% \mathrm{Cl}$ & $\mathrm{RR}$ & $95 \% \mathrm{Cl}$ & $\mathrm{RR}$ & $95 \% \mathrm{Cl}$ & RR & $95 \% \mathrm{Cl}$ & RR & $95 \% \mathrm{Cl}$ \\
\hline \multicolumn{13}{|l|}{ Exposure: proportion of fast-food restaurants } \\
\hline At home & 1.88 & $1.03,3.43$ & 1.76 & $0.96,3.23$ & 0.41 & $0.22,0.78$ & 0.54 & $0.28,1.04$ & 1.32 & $0.56,3.11$ & 1.49 & $0.61,3.61$ \\
\hline Away from home & 1.29 & $0.71,2.35$ & 1.25 & $0.68,2.30$ & 0.54 & $0.27,1.07$ & 0.82 & $0.39,1.69$ & 1.19 & $0.48,2.94$ & 1.52 & $0.60,3.88$ \\
\hline At home and/or away & 1.35 & $0 \cdot 83,2 \cdot 20$ & 1.30 & $0.80,2 \cdot 12$ & 0.48 & $0.29,0.80$ & 0.65 & $0.38,1.10$ & 1.20 & $0.58,2.48$ & 1.41 & $0.66,3.01$ \\
\hline \multicolumn{13}{|l|}{ Exposure: proportion of convenience stores } \\
\hline Drinking SSB $\geq 1$ time/d & 1.49 & $1 \cdot 10,2 \cdot 01$ & 1.45 & $1.08,1.96$ & $1 \cdot 19$ & $0.98,1.45$ & $1 \cdot 18$ & $0.98,1.44$ & 1.62 & $1.07,2.47$ & 1.69 & $1.11,2.57$ \\
\hline
\end{tabular}

Statistically significant estimates $(P<0.05)$ are indicated in bold

*Models are adjusted for age (continuous), sex (female/male), ethnicity (White/Black/South Asian/Other), and free school meals (yes/no).

†Reference category is $<2-3 \mathrm{~d} / \mathrm{week}$.

TReference category is $<2-3 \mathrm{~d} / \mathrm{w} / \mathrm{d}$.
\#Reference category is $<1$ time/d. 
reached statistical significance only for SSB intake. These results add to the small body of work concerning relative measures of the food environment, with previous studies reporting both null ${ }^{(32)}$ and positive ${ }^{(55)}$ associations between the residential or school neighbourhood food environment and fast-food and SSB intakes in young people.

In accordance with our hypothesis, the relative availability of fast-food restaurants or convenience stores in the combined home and school neighbourhoods was more strongly associated with fast food consumed away from home and at home and/or away, as well as with SSB, than the home and school food environments considered separately. Although confidence intervals overlapped, these findings provide some support to Burgoine et al. who found in British adults that the cumulative exposure to fastfood restaurants in residential and work neighbourhoods was more strongly associated with daily fast-food intake than each distinct setting ${ }^{(56)}$. Repeat encounters with a similar type of food establishment across the day and over time may cumulatively impact individuals' knowledge of the options available to them and render some of these more enticing or seemingly more accessible than others ${ }^{(24)}$.

The lack of statistically significant associations between most availability measures and food behaviours may also be explained by the fact that the food environment as measured in our study is only one dimension of food outlet access and use; aspects of proximity, affordability, accommodation (e.g. store opening hours) and sociocultural acceptability may also be important ${ }^{(57)}$. Cowburn et al., for instance, reported that despite having the opportunity to purchase food on the journey between home and school, children did not necessarily do so because they did not have enough money or time ${ }^{(58)}$. It should thus be kept in mind that there is inter-individual variability in how people interact with the food environment ${ }^{(24,59)}$ and that the purchase of food from a given outlet ultimately arises from a complex interaction between adolescents' circumstances at a specific time and the environment ${ }^{(24)}$.

Unmeasured individual, peer, family, school and community-level factors, such as personal taste, preferences, sense of mastery and foods available within schools, as well as parenting style and parents' own food intake could also mediate or moderate the relationship between the food environment and food behaviours ${ }^{(37)}$. In our study uncontrolled confounding by these factors may have masked true associations, while untested effect modification may potentially conceal significant subgroup effects. For example, restrictions on leaving school grounds at lunch time and the use of non-active commuting modes such as the car or bus might have limited the extent to which adolescents could actually access the food outlets surrounding their school. While we could not verify the former hypothesis for lack of data on school policies, we did not find that mode of transportation to school moderated the associations reported here. We also observed inequalities in some food behaviours and some exposure measures by ethnicity and free school meal status, two potential moderators of the food environmentfood behaviour relationship, but interactions were not significant in this sample (data not shown). Alternatively, the null associations we found may be masking heterogeneity in relationships across space, as found in the adult sample of the ORiEL Study ${ }^{(40)}$ and elsewhere ${ }^{(27)}$. Further exploring spatial heterogeneity in how the food environment relates to younger people's eating behaviours is a sound avenue for future research.

Strengths of our study include that home, school and food retail locations were geocoded with high precision (to the address level), thereby reducing spatial error ${ }^{(60)}$. Food environment data were drawn from official council registers collected for regulatory purposes, thus providing high levels of validity in comparison to data from commercial sources ${ }^{(61)}$. Since measures of association are prone to vary depending on the shape and size of the geographical unit studied ${ }^{(62)}$, we tested model robustness when food environment measures were aggregated within 400 and $600 \mathrm{~m}$ road network buffers and found results to be relatively consistent with those presented here. Given policy makers' interest in intervening in the food environment, especially around schools, it seems important to assess associations for different threshold distances. Limitations include that the study area mainly comprised disadvantaged neighbourhoods (see Appendix 1) and that fast-food outlets and convenience stores were ubiquitous in places (see Appendix 2), which may have reduced the amount of heterogeneity in individual and food environment measures, reducing the likelihood of uncovering significant associations. We also were unable to account for children's exposure to food outlets on their commute between home and school, an exposure which has been found to relate to unhealthy food purchases in one study $^{(19)}$, but not in two others ${ }^{(26,30)}$. Investigating the food environment along pupils' commuting routes nevertheless remains a relevant avenue for research, although this should be done with caution since children have been found to often vary the routes they travel between home and school ${ }^{(63,64)}$. Limitations related to food behaviour measures should also be mentioned. We utilized adolescent self-reported dietary intake which, although common in food behaviour studies of young people, can lead to measurement error compared with gold-standard approaches of dietary assessment. Furthermore, the specific question used to assess fast-food intake, although borrowed from the Health and Behaviours in Teenagers Study (HABITS) and other studies ${ }^{(26,44,45)}$ and validated in young people ${ }^{(45)}$, was not validated in the ORiEL sample. It is thus possible that participants misreported their fastfood intake, for instance by under-reporting fast food purchased from independent restaurants, since the question provided examples of chain fast-food outlets only. In that case, true fast-food intake would be underestimated. However, we do not expect such response bias to have 
been differential between high and low consumers, thus our results would be conservative estimates of true associations. Finally, our measure of SSB intake included only fizzy drinks, which might have underestimated true intake since adolescents also consume other types of sugary beverages such as fruit juices, cordials and energy drinks.

In the present study of adolescents from East London, UK, we found limited evidence for an association between the food environment around home and school and fastfood or SSB intake. Where positive associations were observed these were for relative rather than absolute measures of exposure, as seen with the proportion of convenience stores around home and in the combined home and school neighbourhoods being associated with increased SSB consumption. Modifying the local food retail system through increasing diversity in food retailing and reducing the proportion of unhealthy food outlets within the local food environment may be more promising than a simple focus on individual food establishments. Better conceptualization and operationalization of adolescents' dietary behaviours in terms of when, how and what they purchase and consume, and where they do so, is also a worthwhile avenue for future research.

\section{Acknowledgements}

Acknowledgements: The authors would like to thank Nicolas Berger for his invaluable support in the missing data imputation phase, as well as Amanda Fahy, Vanathi Tharmaratnam, Danielle House and Claire Thompson for contributing to the data collection. Financial support: M.S. holds a postdoctoral fellowship from the Canadian Institutes of Health Research (grant number 201311MFE-321141-159944). D.L. holds a postdoctoral skills development fellowship from the UK Medical Research Council (grant number MR/N014588/1). The ORiEL Study was funded by the UK National Institute for Health Research (grant number 09/3005/09). The funders of the study had no role in study design, data collection, data analysis, data interpretation or writing of the paper. Conflict of interest: None. Authorship: M.S. formulated the research question, conducted the analyses and wrote the manuscript. D.L. computed the environmental measures and provided feedback on the analyses and all drafts of the manuscript. N.R.S., C.C. and S.C. provided feedback on the analyses and all drafts of the manuscript. All authors agreed to the final version of the manuscript. Ethics of buman subject participation: This study was conducted according to the guidelines laid down in the Declaration of Helsinki, and all procedures involving human subjects were approved by the Queen Mary University of London Research Ethics Committee (QMREC2011/40), the Association of Directors of Children's Services (RGE110927) and the London Boroughs Research Governance Framework (CERGF113). Headteachers gave written consent for the study to take place within their school, parents gave passive informed consent for their child to participate, and adolescent participants gave written informed assent.

\section{References}

1. World Health Organization (2012) Population-Based Approaches to Childhood Obesity Prevention. Geneva: WHO.

2. Northstone K, Smith AD, Cribb VL et al. (2014) Dietary patterns in UK adolescents obtained from a dual-source FFQ and their associations with socio-economic position, nutrient intake and modes of eating. Public Health Nutr 17, 1476-1485.

3. Lachat C, Nago E, Verstraeten R et al. (2012) Eating out of home and its association with dietary intake: a systematic review of the evidence. Obes Rev 13, 329-346.

4. Braithwaite I, Stewart AW, Hancox RJ et al. (2014) Fast-food consumption and body mass index in children and adolescents: an international cross-sectional study. BMJ Open $\mathbf{4}$, e005813.

5. Bowman SA, Gortmaker SL, Ebbeling CB et al. (2004) Effects of fast-food consumption on energy intake and diet quality among children in a national household survey. Pediatrics 113, 112-118.

6. Public Health England \& Food Standards Agency (2014) National Diet and Nutrition Survey Results from Years 1, 2, 3 and 4 (Combined) of the Rolling Programme (2008/ 2009 - 2011/2012). London: Public Health England.

7. Tedstone A, Targett V, Allen R et al. (2015) Sugar Reduction: The Evidence for Action. London: Public Health England.

8. Craigie AM, Lake AA, Kelly SA et al. (2011) Tracking of obesity-related behaviours from childhood to adulthood: a systematic review. Maturitas 70, 266-284.

9. Mikkila V, Rasanen L, Raitakari OT et al. (2005) Consistent dietary patterns identified from childhood to adulthood: the cardiovascular risk in Young Finns Study. Br J Nutr 93, 923-931.

10. Mazarello Paes V, Hesketh K, O'Malley C et al. (2015) Determinants of sugar-sweetened beverage consumption in young children: a systematic review. Obes Rev 16, 903-913.

11. Glanz K (2009) Measuring food environments: a historical perspective. Am J Prev Med 36, Suppl. 4, S93-S98.

12. Engler-Stringer R, Le H, Gerrard A et al. (2014) The community and consumer food environment and children's diet: a systematic review. BMC Public Health 14, 522.

13. Caspi CE, Sorensen G, Subramanian SV et al. (2012) The local food environment and diet: a systematic review. Health Place 18, 1172-1187.

14. Black C, Moon G \& Baird J (2014) Dietary inequalities: what is the evidence for the effect of the neighbourhood food environment? Health Place 27, 229-242.

15. Fitzpatrick C, Datta GD, Henderson M et al. (2017) School food environments associated with adiposity in Canadian children. Int J Obes (Lobd) 41, 1005-1010.

16. Williams J, Scarborough P, Matthews A et al. (2014) A systematic review of the influence of the retail food environment around schools on obesity-related outcomes. Obes Rev 15, 359-374.

17. He M, Tucker P, Gilliland J et al. (2012) The influence of local food environments on adolescents' food purchasing behaviors. Int J Environ Res Public Health 9, 1458-1471.

18. Shier V, Nicosia N \& Datar A (2016) Neighborhood and home food environment and children's diet and obesity: evidence from military personnel's installation assignment. Soc Sci Med 158, 122-131.

19. Sadler RC, Clark AF, Wilk P et al. (2016) Using GPS and activity tracking to reveal the influence of adolescents' food environment exposure on junk food purchasing. Can $J$ Public Health 107, Suppl. 1, 5346. 
20. Pearce A, Kirk C, Cummins S et al. (2009) Gaining children's perspectives: a multiple method approach to explore environmental influences on healthy eating and physical activity. Health Place 15, 614-621.

21. Wansink B (2004) Environmental factors that increase the food intake and consumption volume of unknowing consumers. Annu Rev Nutr 24, 455-479.

22. Drewnowski A (1989) Sensory preferences for fat and sugar in adolescence and adult life. Ann N Y Acad Sci 561, 243-250.

23. Khan T, Powell LM \& Wada R (2012) Fast food consumption and food prices: evidence from panel data on 5th and 8th grade children. J Obes 2012, 857697.

24. Clary C, Matthews SA \& Kestens Y (2017) Between exposure, access and use: reconsidering foodscape influences on dietary behaviours. Health Place 44, 1-7.

25. Sallis JF \& Glanz K (2009) Physical activity and food environments: solutions to the obesity epidemic. Milbank $Q \mathbf{8 7}, 123-154$.

26. Timperio AF, Ball K, Roberts R et al. (2009) Children's takeaway and fast-food intakes: associations with the neighbourhood food environment. Public Health Nutr 12, 1960-1964.

27. Fraser LK, Clarke GP, Cade JE et al. (2012) Fast food and obesity: a spatial analysis in a large United Kingdom population of children aged 13-15. Am J Prev Med 42, e77-e85.

28. Longacre MR, Drake KM, MacKenzie TA et al. (2012) Fastfood environments and family fast-food intake in nonmetropolitan areas. Am J Prev Med 42, 579-587.

29. Jennings A, Welch A, Jones AP et al. (2011) Local food outlets, weight status, and dietary intake: associations in children aged 9-10 years. Am J Prev Med 40, 405-410.

30. Laska MN, Hearst MO, Forsyth A et al. (2010) Neighbourhood food environments: are they associated with adolescent dietary intake, food purchases and weight status? Public Health Nutr 13, 1757-1763.

31. Davis B \& Carpenter C (2009) Proximity of fast-food restaurants to schools and adolescent obesity. Am J Public Health 99, 505-510.

32. Van Hulst A, Barnett TA, Gauvin L et al. (2012) Associations between children's diets and features of their residential and school neighbourhood food environments. Can J Public Health 103, 9 Suppl. 3, eS48-eS54.

33. Skidmore P, Welch A, van Sluijs E et al. (2010) Impact of neighbourhood food environment on food consumption in children aged 9-10 years in the UK SPEEDY (Sport, Physical Activity and Eating behaviour: Environmental Determinants in Young people) study. Public Health Nutr 13, 1022-1030.

34. Svastisalee C, Pagh Pedersen T, Schipperijn J et al. (2016) Fast-food intake and perceived and objective measures of the local fast-food environment in adolescents. Public Health Nutr 19, 446-455.

35. Buck C, Bornhorst C, Pohlabeln H et al. (2013) Clustering of unhealthy food around German schools and its influence on dietary behavior in school children: a pilot study. Int $J$ Behav Nutr Phys Act 10, 65.

36. An RP \& Sturm R (2012) School and residential neighborhood food environment and diet among California youth. Am J Prev Med 42, 129-135.

37. van der Horst K, Timperio A, Crawford D et al. (2008) The school food environment associations with adolescent soft drink and snack consumption. Am J Prev Med 35, 217-223.

38. Cutumisu N, Traore I, Paquette MC et al. (2017) Association between junk food consumption and fast-food outlet access near school among Quebec secondary-school children: findings from the Quebec Health Survey of High School Students (QHSHSS) 2010-11. Public Health Nutr 20, 927-937.

39. Barrett M, Crozier S, Lewis D et al. (2017) Greater access to healthy food outlets in the home and school environment is associated with better dietary quality in young children. Public Health Nutr 20, 3316-3325.

40. Clary C, Lewis DJ, Flint E et al. (2016) The local food environment and fruit and vegetable intake: a geographically weighted regression approach in the ORiEL Study. $A m \mathrm{~J}$ Epidemiol 184, 837-846.

41. Clary CM, Ramos Y, Shareck M et al. (2015) Should we use absolute or relative measures when assessing foodscape exposure in relation to fruit and vegetable intake? Evidence from a wide-scale Canadian study. Prev Med 71, 83-87.

42. Mason KE, Bentley RJ \& Kavanagh AM (2013) Fruit and vegetable purchasing and the relative density of healthy and unhealthy food stores: evidence from an Australian multilevel study. J Epidemiol Community Health 67, 231-236.

43. Smith NR, Clark C, Fahy AE et al. (2012) The Olympic Regeneration in East London (ORiEL) study: protocol for a prospective controlled quasi-experiment to evaluate the impact of urban regeneration on young people and their families. BMJ Open 2, e001840.

44. Wardle J, Sutton S \& Jarvis M (1998) HABITS - The Health and Behaviours in Teenagers Study. London: London Health Behaviour Unit, Department of Epidemiology and Public Health, University College London.

45. Pereira MA, Kartashov AI, Ebbeling CB et al. (2005) Fastfood habits, weight gain, and insulin resistance (the CARDIA study): 15-year prospective analysis. Lancet 365, 36-42.

46. Lake AA, Burgoine T, Greenhalgh F et al. (2010) The foodscape: classification and field validation of secondary data sources. Health Place 16, 666-673.

47. Ordnance Survey (2011) OS MasterMap Address Layer 2. https://www.ordnancesurvey.co.uk/docs/technical-specific ations/os-master-map-address-layer-technical-specification. pdf (accessed August 2014).

48. Bridle-Fitzpatrick S (2015) Food deserts or food swamps?: a mixed-methods study of local food environments in a Mexican city. Soc Sci Med 142, 202-213.

49. Lamb KE \& White SR (2015) Categorisation of built environment characteristics: the trouble with tertiles. Int J Behav Nutr Phys Act 12, 19.

50. Carpenter JR \& Kenward MG (2013) Multiple Imputation and Its Application, 1st ed. Chichester: John Wiley \& Sons.

51. StataCorp (2017) Stata Multiple Imputation Reference Manual - Release 15. College Station, TX: Stata Press.

52. McNutt LA, Wu C, Xue X et al. (2003) Estimating the relative risk in cohort studies and clinical trials of common outcomes. Am J Epidemiol 157, 940-943.

53. Sullivan TR, Lee KJ, Ryan P et al. (2017) Multiple imputation for handling missing outcome data when estimating the relative risk. BMC Med Res Methodol 17, 134.

54. Huang JG, Lu XX \& Sellers JM (2007) A global comparative analysis of urban form: applying spatial metrics and remote sensing. Landscape Urban Plan 82, 184-197.

55. Babey S, Wolstein J \& Diamant AL (2011) Food Environments Near Home and School Related to Consumption of Soda and Fast Food. Los Angeles, CA: UCLA Center for Health Policy Research.

56. Burgoine T, Forouhi NG, Griffin SJ et al. (2014) Associations between exposure to takeaway food outlets, takeaway food consumption, and body weight in Cambridgeshire, UK: population based, cross sectional study. BMJ 348, g1464.

57. Penchansky R \& Thomas JW (1981) The concept of access: definition and relationship to consumer satisfaction. Med Care 19, 127-140.

58. Cowburn G, Matthews A, Doherty A et al. (2016) Exploring the opportunities for food and drink purchasing and consumption by teenagers during their journeys between home and school: a feasibility study using a novel method. Public Health Nutr 19, 93-103.

59. Paquet C, Dubé L, Gauvin L et al. (2010) Sense of mastery and metabolic risk: moderating role of the local fast-food environment. Psychosom Med 72, 324-331.

60. Chaix B, Merlo J, Evans D et al. (2009) Neighbourhoods in eco-epidemiologic research: delimiting personal exposure 
areas. A response to Riva, Gauvin, Apparicio and Brodeur. Soc Sci Med 69, 1306-1310.

61. Cummins S \& Macintyre S (2009) Are secondary data sources on the neighbourhood food environment accurate? Case-study in Glasgow, UK. Prev Med 49, 527-528.

62. Fotheringham AS \& Wong DWS (1991) The modifiable areal unit problem in multivariate statistical-analysis. Environ Plan A 23, 1025-1044.

63. Stewart T, Schipperijn J, Snizek B et al. (2017) Adolescent school travel: Is online mapping a practical alternative to GPS-assessed travel routes? J Transport Health 5, 113-122.

64. Harrison F, Burgoine T, Corder K et al. (2014) How well do modelled routes to school record the environments children are exposed to? A cross-sectional comparison of GIS-modelled and GPS-measured routes to school. Int J Health Geogr 13, 5.

\section{Appendix 1}

Descriptive statistics for the Olympic Regeneration in East London (ORiEL) sample*

\begin{tabular}{|c|c|c|}
\hline Characteristic & $\%$ & $\begin{array}{c}\% \\
\text { missing }\end{array}$ \\
\hline Age (years) & \multirow{2}{*}{\multicolumn{2}{|c|}{$14 \cdot 1^{0.0}$}} \\
\hline Mean & & \\
\hline SD & \multicolumn{2}{|r|}{0.32} \\
\hline Female & 43.3 & 0.0 \\
\hline Ethnicity & & 0.9 \\
\hline White UK & $16 \cdot 9$ & \\
\hline South Asian & $22 \cdot 9$ & \\
\hline Black & $22 \cdot 7$ & \\
\hline Other & $37 \cdot 6$ & \\
\hline Have free school meals & 33.2 & $2 \cdot 3$ \\
\hline Fast-food intake & & \\
\hline$\geq 2-3 \mathrm{~d} /$ week at home & $27 \cdot 3$ & $17 \cdot 5$ \\
\hline$\geq 2-3 \mathrm{~d} /$ week away from home & $25 \cdot 5$ & $18 \cdot 0$ \\
\hline $\begin{array}{l}\geq 2-3 \mathrm{~d} / \text { week at and/or away from home } \\
\text { SSBt }\end{array}$ & 36.5 & $18 \cdot 5$ \\
\hline$\geq 1$ time $/ \mathrm{d}$ & $46 \cdot 9$ & $17 \cdot 0$ \\
\hline School borough & & \\
\hline Tower Hamlets & $25 \cdot 6$ & \\
\hline Hackney & $24 \cdot 0$ & \\
\hline Barking and Dagenham & $19 \cdot 9$ & \\
\hline Newham & 30.5 & \\
\hline $\begin{array}{l}\text { Relative income deprivation in residential } \\
\text { neighbourhood }\end{array}$ & & $14 \cdot 1$ \\
\hline Quintile 1 (high deprivation) & $50 \cdot 4$ & \\
\hline Quintile 2 & 31.6 & \\
\hline Quintile 3 & $14 \cdot 6$ & \\
\hline Quintile 4 & 2.8 & \\
\hline Quintile 5 (low deprivation) & 0.7 & \\
\hline
\end{tabular}

SSB, sugar-sweetened beverage.

${ }^{*}$ Descriptive statistics are based on complete cases for each variable. †SSB approximated with intake of fizzy drinks.
Appendix 2

Food environment characteristics and percentage missing for the Olympic Regeneration in East London (ORiEL) sample*

\begin{tabular}{|c|c|c|c|c|c|c|}
\hline $\begin{array}{l}\text { Food environment } \\
\text { measure }\end{array}$ & Median & IQR & Range & $\begin{array}{l}n \text { with } \\
0 \text { food } \\
\text { outlet }\end{array}$ & $\begin{array}{l}\% \text { with } \\
0 \text { food } \\
\text { outlet }\end{array}$ & $\begin{array}{c}\% \\
\text { missing }\end{array}$ \\
\hline \multicolumn{7}{|l|}{$\begin{array}{l}\text { Availability of fast- } \\
\text { food restaurants } \\
\text { around home }\end{array}$} \\
\hline $\begin{array}{l}\text { Absolute } \\
\text { Relative } \neq\end{array}$ & $\begin{array}{l}10 \cdot 0 \\
0.27\end{array}$ & $\begin{array}{l}13 \cdot 0 \\
0 \cdot 13\end{array}$ & $\begin{array}{l}0-46 \\
0-1\end{array}$ & 178 & $6 \cdot 7$ & $\begin{array}{l}14 \cdot 0 \\
14 \cdot 0\end{array}$ \\
\hline \multicolumn{7}{|l|}{$\begin{array}{l}\text { Availability of fast- } \\
\text { food restaurants } \\
\text { around school }\end{array}$} \\
\hline $\begin{array}{l}\text { Absolute† } \\
\text { Relative } \neq\end{array}$ & $\begin{array}{c}10 \cdot 0 \\
0.22\end{array}$ & $\begin{array}{c}12 \cdot 0 \\
0 \cdot 10\end{array}$ & $\begin{array}{l}0-24 \\
0-0.41\end{array}$ & 311 & $10 \cdot 1$ & $\begin{array}{l}0.0 \\
0.0\end{array}$ \\
\hline \multicolumn{7}{|l|}{$\begin{array}{l}\text { Availability of fast- } \\
\text { food restaurants } \\
\text { around home } \\
\text { and school }\end{array}$} \\
\hline $\begin{array}{l}\text { Absolute } \\
\text { Relative }\end{array}$ & $\begin{array}{c}18.0 \\
0.25\end{array}$ & $\begin{array}{c}16 \cdot 0 \\
0 \cdot 10\end{array}$ & $\begin{array}{l}0-62 \\
0-0.43\end{array}$ & 55 & $2 \cdot 1$ & $\begin{array}{l}14 \cdot 0 \\
14 \cdot 0\end{array}$ \\
\hline \multicolumn{7}{|l|}{$\begin{array}{l}\text { Availability of } \\
\text { convenience } \\
\text { stores around } \\
\text { home }\end{array}$} \\
\hline $\begin{array}{l}\text { Absolute } † \\
\text { Relative } \ddagger\end{array}$ & $\begin{array}{c}10 \cdot 0 \\
0.26\end{array}$ & $\begin{array}{l}11.0 \\
0.15\end{array}$ & $\begin{array}{l}0-39 \\
0-1\end{array}$ & 108 & $4 \cdot 1$ & $\begin{array}{l}14 \cdot 0 \\
14 \cdot 0\end{array}$ \\
\hline \multicolumn{7}{|l|}{$\begin{array}{l}\text { Availability of } \\
\text { convenience } \\
\text { stores around } \\
\text { school }\end{array}$} \\
\hline Absolute $†$ & 11.0 & $8 \cdot 0$ & $0-35$ & 97 & 4.5 & 0.0 \\
\hline Relative $\neq$ & 0.26 & 0.18 & $0-1$ & & & 0.0 \\
\hline \multirow{2}{*}{\multicolumn{7}{|c|}{$\begin{array}{l}\text { Availability of } \\
\text { convenience } \\
\text { stores around } \\
\text { home and school }\end{array}$}} \\
\hline & & & & & & \\
\hline Absolute† & $19 \cdot 0$ & $16 \cdot 0$ & $0-64$ & 35 & $1 \cdot 3$ & $14 \cdot 0$ \\
\hline Relativeł & 0.26 & 0.12 & $0-1$ & & & $14 \cdot 0$ \\
\hline
\end{tabular}

IQR, interquartile range.

*Descriptive statistics are based on complete cases for each variable. $\dagger$ Absolute availability is the number of fast-food restaurants or convenience stores in a given buffer.

†Relative availability is the proportion of all food establishments that are fastfood restaurants or convenience stores in a given buffer. 